\title{
Study on the Necessity and Strategy of Establishing a Nursery School Under the Comprehensive Two-child Policy*
}

\author{
Xiaojia Pang \\ Xi’an Fanyi University \\ Xi'an, China
}

\author{
Huining Guo \\ Xijing University \\ Xi'an, China
}

\begin{abstract}
China has fully implemented the two-child policy in 2016, the "family independent care" mode adopted by children aged 0-3 during the one-child period has not been adapted to the new family structure, therefore, it is urgent to establish a nursery school. The first thing to solve in the establishment of the nursery school is to identify the qualifications of the institution and the insufficient legal policies, then according to the density of the resident population, the formation of street and community as the main body of several nurseries.
\end{abstract}

Keywords-comprehensive two-child policy; establishing nursery school; necessity; strategy research

\section{INTRODUCTION}

China has fully implemented the two-child policy in 2016, which is a major strategic adjustment and layout for China's economic and social development and coping with the aging of the population. This policy is also an important task to build a moderately prosperous society in all respects. But "no one can support a second child" is the main obstacle of the policy's implementation. In order to better implement the two-child policy, the society must provide the family with corresponding childcare services and share the pressure of raising the second child for the family. Therefore, it is imperative to establish a nursery. This study aims at elaborating the necessity of component nursery under the comprehensive two-child policy, and at the same time, it gives specific suggestions from the school-running qualification and school-running mode.

\section{THE NECESSITY OF ESTABLISHING A NURSERY} SCHOOL UNDER THE COMPREHENSIVE TWO-CHILD POLICY

\section{A. People of Child-bearing Age Are Afraid to Have} Children Because Their Children Are Uncared for

The comprehensive implementation of the two-child policy will slow down the aging process of China's

*[Scientific Research Item] This paper is the periodical achievement of 2017 Shan xi provincial department of education humanities and social science research plan project that named "Study on the strategy of constructing new nurseries in Shan xi under the universal two-child policy." (Item Number: 17JK0981) population in a timely manner and make necessary preparations for the sufficient labor force of the young and middle-aged in the future. The whole society, especially couples of childbearing age, should respond positively to this policy and assume corresponding social responsibilities. However, from the current situation of childbirth, this good policy of benefiting the country and the people has encountered many obstacles in its implementation, among which the main obstacle is that the second child is uncared for. According to the Shanghai women's development needs survey report on the 13th five-year plan issued by Shanghai women's federation in 2015 [1], there are currently 2.08 million women of child-bearing age in Shanghai. From March 2014 to October 2015, when the two-child policy was implemented, only 30,000 families applied for a twochild policy;

$54.2 \%$ of women of child-bearing age under 45 said they were unwilling to have two children, and $58.2 \%$ of women of child-bearing age said that the economic cost of raising children was the first reason why they did not want to have two children.in addition to the high economic cost, the second most important thing is that the second child is uncared for $29.5 \%$ of women of child-bearing age are reluctant to have another child because of this concern, and the higher the education level, the more serious the problem is. Among women with a bachelor's degree or above, $41.2 \%$ were unable to respond to the two-child policy because their children were not cared for. At the beginning of 2017, one year after the implementation of the comprehensive twochild policy, the survey report of the all-china women's federation shows that [2] more than half of the one-child families in China have no intention of having a second children, having no one to look after them is one of the important factors to decide whether to have a second child. In view of the current situation, children aged 0-3 still mainly adopt the "family independent care" mode, which is not included in the official education system of the state.

\section{B. At Present, Children Aged 0-3 Are in a Difficult Situation of "Family Independent Care"}

With the promotion of the two-child policy, the "family independent care" mode of 0-3-year-olds, which has lasted for more than 30 years, is no longer suitable. Due to the busy 
work of young couples at ordinary times, after the birth of a child, the first child is usually brought to the age of 3 by grandparents or grandparents until the child enters the kindergarten to accept education [3].This three years, grandma and grandpa take care of the child is very tired, try to stick to three years, if to look after the second child to 3 years old again, it's difficult for most of the old people, along with the increase of age, energy shortage, poor health and other obvious; at the same time, in order to help their kid to look after little baby, some old people to leave their homes, some old man with his lover separation, almost no their own retirement, many old people are no longer willing to help their kid to look after baby. In this case, it is more difficult for the elderly to continue to take care of the second child, and many couples of child-bearing age are afraid to have a second child.

According to the report that theme of "two-child financial books: children born, who will bring them? by "economic half hour" on March 30, 2016,Their online survey of 12,000 two-child households found that $86.5 \%$ of families have had a second child but no one has taken care of the child, which is the biggest problem for the family of two children. At present the national public kindergarten only recruit children over the age of 3, 0 to 3 years, in addition to the parents help to take care of, almost no country formal childcare facilities, it became the important factors that affect whether family to have the second child. Some private kindergartens have been aware of this problem and have taken the initiative to take part in the children care, such as to allow 2 to 3 years old children in kindergartens, but because of the limitation of number of private kindergartens and ability to young children into a managed class is very limited, especially in some big cities, many parents is not necessarily to get in the kindergarten a year or two in advance in line, it has become whether to second child of the family, it's another worry about having a second child. In recent years, it is still popular to send children aged 0-3 to early education institutions. However, early education institutions do not have any permission from the local education department and only register in the industrial and commercial departments. In other words, they do not have any qualifications for running a school, but in the guise of early education, they carry out pre-school education, which is expensive and has a large variety of safety hazards [4].All these factors limit the implementation of the two-child policy.

With the implementation of the comprehensive two-child policy, the number of children aged 0-3 will inevitably increase. Therefore, more attention should be paid to the conservation of children aged $0-3$, which is not only a family problem, but also a social problem. The best solution is to integrate social resources - create nurseries, to solve the family problems.

\section{STRATEGIC RESEARCH ON THE ESTABLISHMENT OF NURSERY SCHOOLS}

"Nursery" as keywords to search in China journal fulltext database, a total of 1423 documents related to retrieve, nearly five years of literature is only $172,12.1 \%$ of the total, it shows that in recent years, our attention to the nursery is not high, but the implementation of the two-child policy in 2016 has forced us to rethink the problem of starting a nursery.

After sorting out the literature and searching the relevant materials, it is found that the existing nurseries in China mainly include "family nurseries" and "large nurseries", and a small number of nurseries exist in enterprises and institutions (later called "unit nurseries").Family nursery is a profession which emerged in nearly a decade, it is mainly based on community, the location is in commonly inside the village, the advantage is near children's home, convenient parents shuttle, smaller (generally no more than ten children), for children to take care of considerate, reasonable charge at the same time, usually is 250-300 yuan/month [5], but the defect is "family nursery is in private, profit as the main purpose, part of the" family day care "in order to save costs, existence of unlicensed operation, lack of teaching organization, moreover, "family nursery" mainly takes "looking after children" as its work content, and lacks professional child-care work. "Large nursery" is a welfare qualitative child care institutions, such as" Chinese welfare nursery in Shanghai, but the number of such nursery is less, far cannot satisfy the demand of young parents after two child policy implementation. "Unit nursery" is enterprises and institutions in order to solve the trouble back at home of employee, dual-career couples to improve the staff's working efficiency and the enterprise belonging to run for the purpose, this kind of nursery school belongs to unit of an affiliate product, it's easy to have a regulatory issues and child care and education professional problems. In view of this, the following problems must be solved to establish a nursery school at present.

\section{A. The Educational Qualification of the Nursery School}

The existing problems of the educational qualification of a nursery school are shown in two aspects:

First, competent institutions lack the corresponding qualifications for running schools. For example, local street offices (hereinafter referred to as street offices) and communities do not have the qualifications granted by local education departments. Without the permission of relevant laws and policies, street offices and communities cannot intervene in the process of establishing a nursery school. In some places the education department has even halted the creation of street creches in the 1980s, which is a shame.

Second, the qualification and conditions of "family nurseries" and "unit nurseries". Reform and opening up has given rise to many new types of private and foreign capital enterprise, the enterprise itself did not undertake the nursery, inexperience, if now began to demand that all new nursery, will surely increase enterprise economic burden, and is not conducive to enterprise fast development, therefore it is not recommended for these enterprises to form a nursery school. At the same time, since China has not implemented the policy of state-owned enterprises and public institutions undertaking nursery schools in the past 30 years, that cause now when most of the state-owned enterprises in the construction plan and don't have much to consider this 
problem, many institutions have close nursery, so return all state-owned enterprises and institutions to undertake the nursery school is clearly not reality, only a small number of competent units can be encouraged to resume the opening of nursery school, which can be developed in a flexible and diversified manner depending on the nature of the units and the economic situation. In addition, due to the lack of direct supervision from education related departments, "family nurseries" and "unit nurseries" are prone to some management problems that are not conducive to children's growth and development. Such incidents as the "ctrip child abuse case" have exposed the lack of national and local governments' regulations on the supervision of child care centers.

To solve the problem of the above management qualification, we need to do is in the guiding ideology of "to the children for this", for the purpose of "to ensure the personal safety and health of body and mind of children, promote the healthy and happy growth of children", to formulate and promulgate for 0-3 years old children wang education law regulations. To clarify the social nature of the nursery school, the organizers of the nursery school, the funds for the establishment, the competent departments, and the relationship between the nursery school and the kindergarten, so as to standardize the opening, management and operation of the nursery.

To be specific, the social nature of the nursery is to solve the problem of profitability and non-profit (welfare).The conservation institute in Japan was developed as a non-profit charity and still exists in this form [6].The advantage of this model lies in that it can take into account the early education of families of different economic levels and realize the fairness and justice of education. In view of the unbalanced economic income of Chinese households, we can have both for-profit and non-profit (welfare) nurseries, and the difference is that it's targeted at different objects. For-profit nurseries are aimed at families with good economic conditions and abundant labor force. Nonprofit (welfare) nurseries are designed for families living and struggling financially. Therefore, the legal regulations also need to clearly state the entry conditions of two types of nurseries. Parents apply for admission according to their actual conditions, and local governments will conduct a detailed investigation of the children's family conditions to determine which type of nursery they should enter. Therefore, the funding sources of the two types of nurseries should also be different. In general, the state and local governments should vigorously support the financial support of children aged 0 3 , given the different natures of the nursery, the cost of profitability nursery mainly borne by the family, the nonprofit (welfare) of nursery mostly funded by national and local financial allocation, to the family burden is complementary, expenses borne by the family may be set according to the corresponding standards, for example, according to the gross income of the family in the previous year to divide the grades. As for the problem of the educational subject of the nursery school, it is recommended to encourage the establishment of nurseries by various bodies, such as street offices, large communities, competent enterprises, institutions and individuals. The state and local governments need to carry out strict examinations on the qualifications and conditions of school-running entities. The competent department of the nursery school is the ministry of education of China and the competent departments of various local education at all levels. The administrative functions of different departments should be clearly defined, for example, the ministry of education should play a role of policy guidance, and local education departments should be responsible for specific education supervision and management functions. Nursery schools and kindergartens have both connection and difference, and the connection between the two is: they belong to the community of child care and education, whose purpose is the same, both of which promote the healthy and happy growth of children. The difference lies in: first, there is a difference between the nursery school and the kindergarten in the emphasis of protecting and teaching children. In comparison, the nursery in the upbringing of children at the same time, pay more attention to the conservation work of children, kindergarten in the conservation work of children at the same time, more emphasis on children's education work [7].Second, there is a difference of the methods of care and education, nursery to safeguard the health of children as their top priority, emphasized through daily life activities to cultivate children's language, action and cognitive ability, more outstanding the infant wang, health care, family support in the fields of theory and practice skills. Kindergartens put more emphasis on developing children's abilities through games, shaping good characters, and highlighting theories and practical skills related to children's education. So the requirements for teachers are different.

\section{B. The Formation Mode of the Nursery School}

In combination with the practical situation of the above and the present situation of the development of urbanization, according to the intensity of population lives to consider whether to form a nursery, and take the street office and the community as the organizer of the school, adhere to the principle of combining public and private. Funds shall be jointly borne by the state and the family, and some of the expenses shall be included in the central and local financial expenditures, while the remaining expenses shall be borne by the family; whether public or private, we should generally follow the principle of uniform charging standards, and at the same time increase the state's financial investment in preschool education, on the one hand, it can effectively reduce the family economic burden; on the other hand, it can increase the salary and treatment of nursery teachers and reduce the mobility of professional teachers.

There are two ways to set up a nursery in a town. One is to establish a public nursery school in a town with a relatively small resident population, scattered living pattern and large mobility. In the idea of running a nursery school, we adhere to the basic idea of putting children first, caring for children, develop intelligence, ensure health and loving work and dedication. In terms of target, on the basis of absorbing the fine traditions of the original nursery, we should keep pace with the times and establish high-quality 
nurseries. Those with local characteristics can be recognized by local students, parents and the society. After several years of development, several key demonstration nurseries can be set up in various places, which can be used as a model for the establishment of nurseries and form a certain social influence. In terms of organization and management, the nursery school is directly led and established by the street office, which is responsible for the allocation and management of teachers and various facilities. In terms of personnel system, a detailed employment system is formulated. from the director to ordinary employees, the system of employment responsibility is adopted, and it is included in the normal preschool education management system of education department.to reward nurseries and responsible persons that be praised by parents and society; on the contrary, those who are less responsive to their parents and society should be held accountable, and the best and the worst should be eliminated, so as to optimize the teaching staff and improve the quality of the premises. According to the "economy and a half hours" reporter survey of part of the garden of Shanghai, the Shanghai many streets have the capability and conditional and willing to undertake, the main problem is that without the support of relevant policies and laws, so that can't be legal founder. For example, the eastern construction nursery school founded by Weifang street in Pudong new area of Shanghai has a history of 35 years, but was suspended in 2015 due to lack of educational qualification. Therefore, it can be seen that, if relevant policies and laws are adopted as the guarantee, it is feasible to establish public kindergartens in urban areas, especially large and medium-sized cities, with street offices as the organizer.

At the 24th meeting of the 12th standing committee of the National People's Congress in November 2016, the decision on amending the law of the People's Republic of China on the promotion of education was deliberated and adopted. With the support of this bill, the private sector should be encouraged to participate in the development of education for children aged 0-3.So another way to set up a nursery school is to introduce high-quality private kindergartens in large and mature communities, especially those where young people are concentrated. The idea and goal of running a nursery school are consistent with that of the public nursery. In constituent form, these private nursery schools can come from early education organization integration, and also can be formed by the region influential private kindergarten through expanded function, but no matter how to bid the nursery must be able to do the qualification approved by the local education department. In terms of the introduction method, the community committee and the owner committee of each community shall take the lead, and all residents shall participate in the bidding. Upon the consent of more than two-thirds of the residents, the bidding nursery can be formally introduced. On management, bid successful nursery sign a contract with the community, in the garden for the record, and accept the direct supervision of the owners, the owners' committee and the community, by the director is responsible for the daily work, and also into formal education department of pre-school education management system. Those who have been hired to run nurseries with poor conditions in the community shall be ordered to stop operation and make rectification within a time limit.

\section{CONCLUSION}

The unattended birth of children hinders the promotion of the two-child policy. In order to solve this problem, we must integrate social resources and establish a nursery school. First, the key problems is to do qualification, to formulate and promulgate special education law regulations, clear social nature of the nursery and the organizer of running a school, so as the funds, and the departments, also the relationship between the nurseries and kindergartens. The second problem is the model of running the nursery school. Street - run schools and community - run schools can be adopted respectively according to different situations. Only in this way can we gradually promote the start of nursery schools and provide strong support for the implementation of the two-child policy.

\section{REFERENCES}

[1] Thepaper.cn (Shanghai). Survey on the willingness of married women of child-bearing age in Shanghai: 15 percent want to have a second child, while half say no.[EB/OL].http://news.163.com/15/0319/14/AL2UJ79T00014SEH.h tml.2017-4-5.

[2] Xinhuanet reporter investigation: comprehensive second year of the first anniversary of the birth of the intention low? [EB/OL].[2017-45]. http://news.xinhuanet.com/local/ 201701/04/c_129431439.htm.2017-5-30.

[3] Feng Xiaoxia, Zhou Jing. Building national wealth - introduction to the first UNESCO world conference on child care and education[J].1 rd ed.Pre-school education study.2011,pp:20-28.

[4] Liu Linfang. Problems and countermeasures in the development of early education institutions in China[J].10 rd ed.Education to explore.2012,pp:138-140. Startup network. how to start a family nursery, [EB/OL].http://www.795.com.cn/wz/70749.html.2017-1023.

[5] Liu Xiangying. The historical evolution and reform trend of preschool $\begin{array}{lll}\text { education system in Japan. } & \text { [EB/OL] }\end{array}$ http://mp.weixin.qq.com/s?_biz=MzI5NTg1MzUzNg==\&mid=2247 485410\&idx $=1 \& \mathrm{sn}=5267 \mathrm{e} 9 \mathrm{e} 19531 \mathrm{e} 07 \mathrm{~d} 362 \mathrm{cdeb} 28 \mathrm{c} 36 \mathrm{f} 45 \mathrm{~b} \& \mathrm{chksm}=$ ec4c0b6ddb3b827bd301b11f62746f63008e26edbfdde22955a29e2167 86fd9cb84274be9585\&mpshare $=1 \&$ scene $=23 \&$ srcid=1025Ti8G4tspy uDNpSx4ioM7\#rd.2017-12-18.

[6] Li Shenglan. Preschool education[M].Shanghai: east China normal university press.2016,pp:49. 